\title{
ANATOMICAL AND FUNCTIONAL EVALUATION OF DISTAL END RADIUS FRACTURES MANAGED BY VOLAR PLATING: A PROSPECTIVE STUDY
}

Tank Gyaneshwar, Gupta Amit Kumar, Ahmed Parvez, Singh Gajraj, Jaiswal Shantanu, Anish Kumar

1. Assistant Professor \& Head, Department of Orthopaedics, L.L.R.M. Medical College, Meerut (U.P.), India.

2. Junior Resident, Department of Orthopaedics, L.L.R.M. Medical College, Meerut (U.P.), India.

3. Associate Professor, Department of Orthopaedics, L.L.R.M. Medical College, Meerut (U.P.), India.

4. Lecturer, Department of Orthopaedics, L.L.R.M. Medical College, Meerut (U.P.), India.

5. Senior Resident, Department of Orthopaedics, L.L.R.M. Medical College, Meerut (U.P.), India.

6. Senior Resident, Department of Orthopaedics, L.L.R.M. Medical College, Meerut (U.P.), India.

\section{CORRESPONDING AUTHOR}

Dr. Gyaneshwar Tank,

Asst. Prof \& Head,

Dept. of Orthopaedics,

L.L.R.M. Medical College, Meerut (U.P.), India.

E-mail: gyaneshwartonk@gmail.com

Ph: 00919897600445.

ABSTRACT: BACKGROUND: Fractures of distal end radius are the most common fractures of the upper extremity, encountered in orthopaedic practice. The goal of treatment has always been to restore the anatomy of the radius i.e. length, tilt, inclination and joint surface. Fixation of these fractures by volar plating provides restoration of distal radial anatomy and most consistent correction of displacement. The purpose of this study was to evaluate the functional outcome of patients with distal end radius fractures managed operatively by volar plating.

METHODS: Between August 2007 and March 2012, eighty patients with distal end radius fractures were treated with volar fixed-angle locking plate. Fractures were classified according to the AO/ASIF classification system as type $A(n=16), B(n=12)$ and $C(n=52)$. Anatomical evaluation was done by Sarmiento's modification of Lind Storm criteria while clinical and functional outcome was done by demerit point system of Gartland and Werley with Sarmiento et al's modification. RESULTS: The average follow up of patients was 62.5 weeks. On anatomical evaluation at final follow up we found that 68 patients (85\%) had excellent restoration of anatomy, $8(10 \%)$ had good and $4(5 \%)$ had fair restoration of anatomy. Functionally 60 patients $(75 \%)$ had excellent, $12(15 \%)$ had good and $8(10 \%)$ had fair results. Poor function correlated with residual displacement and poor patient compliance. 9 patients had joint stiffness and 3 had paresthesia in median nerve distribution and 2 had reflex sympathetic dystrophy. CONCLUSION: The treatment of intra and extra-articular fractures of the distal radius with a volar plating system have an excellent to good anatomical restoration of anatomy and excellent functional outcomes. This treatment is associated with a very small and statistically insignificant loss of volar tilt, radial inclination and radial length upon comparison of immediate postoperative alignment with that seen after more than 1 year follow-up. These results suggest that stabilizing the fracture with volar plating is a very effective method.

KEY WORDS: Radius fractures, volar plate, treatment outcome, distal end radius.

INTRODUCTION: Distal end radius fractures accounts for one sixth of all fractures presented in emergency rooms $[1,2,3]$. Distal end radius fracture have an approximate incidence of 1:10,000 
people and represent $17 \%$ of all skeletal fractures and $75 \%$ of forearm fractures [4]. There are three main peaks of fracture distribution: the first peak is in children ages 5 to 14 years, the second is in males under age 50 years, and the third peak is in females over the age of 40 years. There seems to be a growing incidence of these fractures in all three groups with the sharpest increase seen in both elderly females and younger adult males [5,6,7]. Difference in the two peak incidences indicates that these fractures represent two very different injuries: one, an insufficiency fracture in elderly patients, and the other is a traumatic injury in younger males. For years distal end radius fractures were injuries assumed to warrant no more than a cast following Colles' writings that "They will at some remote period again enjoy perfect freedom in all of its motions and be completely exempt from pain". Unless certain treatment criteria are met, these fractures will not do well and the result will be a primarily stiff, dysfunctional wrist. This point has been made repeatedly since Gartland and Werley's [8] classic treatise in 1951, highlighted in reports by Frykman [9] and later by Knirk and Jupiter [10].

Close reduction and cast immobilization has been the mainstay of treatment of these fractures but malunion of fracture and subluxation /dislocation of distal radio-ulnar joint resulting in poor functional and cosmetic results is the usual outcome [11]. The residual deformity of wrist adversely affects wrist motion and hand function by interfering with the mechanical advantage of the extrinsic hand musculature [12]. It may cause pain, limitation of forearm motion, and decreased grip strength as a result of arthrosis of the radiocarpal and distal radioulnar joints [13].

As surgical treatment ensures more consistent correction of displacement and maintenance of reduction, this study evaluates the anatomical and functional outcome of open reduction and volar plate fixation in the management of fracture distal end radius in eighty patients.

MATERIAL AND METHODS: Between August 2007 and March 2012, eighty patients of distal end radius fractures were treated with volar locked plate. The study was a prospective study carried out on the patients with fractures of the distal end radius, attending the outdoor and the emergency services of the Department of Orthopaedics in our institution. The inclusion criteria were; the patients presented within 3 weeks of injury, patients with mature skeleton, patients who did not have other associated fractures in ipsilateral upper limb and the patients who gave their consent to undergo the procedure. The exclusion criteria were patients with co-morbid conditions like head injury or chest injury preventing surgical intervention or making patients non compliant for post operative physiotherapy and follow up, patients with more than 3 weeks duration of injury, patients with local tissue condition making the surgery inadvisable. All the patients were subjected to clinical examination. Radiographic evaluation of the affected and the normal side was done at the time of injury with the anterio-posterior and lateral views. The radiographs were assessed in terms of loss of palmar tilt or presence of dorsal tilt, radial shortening and loss of radial inclination. Fractures were classified as according to the AO Classification into type A (extra-articular), type B (partial articular) and type C (complete articular).

All patients were operated under regional anesthesia except five where regional anesthesia was contraindicated and general anesthesia was given. Our standard practice was to give preoperative prophylactic intravenous antibiotic and usage of tourniquet and bipolar diathermy for homeostasis. The standard volar approach was undertaken to reduce and fix the fragments. In cases initially approaching the radial styloid fragment, dissection was done 
between the flexor carpi radialis tendon and radial artery. For the die-punch volar fragment, dissection was done between the median nerve and flexor carpi radialis tendon. Open reduction was performed with the aid of intrafocal leverage, traction by an assistant/distractor, and provisional fixation by temporary K-wires followed by definitive volar locking plate and screws. Image intensifier was used to assist the evaluation of fracture reduction and fixation. When the ulnar styloid was fractured below its base, the distal ulna was approached either dorsally between the fifth (extensor digiti quinti) and sixth (extensor carpi ulnaris) extensor compartments, where access could be gained to the ulnar styloid and triangular fibrocartilage complex, or ulnarly between the extensor carpi ulnaris and flexor carpi ulnaris tendons. A tension-band wire was passed through the proximal ulna and through the ulnar styloid fragment or small K-wires used to fix the fragment to shaft.

Postoperatively radiographs were taken and the limb was kept elevated and passive exercises of finger were started immediate post operatively. Active exercises of finger, wrist, and elbow were started as early as possible. The patients were followed up initially postoperatively at one, three, six weeks and then at three monthly regular intervals. Clinical, radiological and functional evaluation was done at every visit of the patient. Radiological assessment was done in terms of residual dorsal angulation, residual radial shortening and loss of radial inclination and the results were graded according to the Sarmiento's modification of Lind Strom Criteria [14][table 1]. These parameters were assessed during the follow up of the patient for the quality of reduction and the ability of the technique to maintain the reduction. Functional evaluation of the patients was done according to the demerit point system of Gartland and Werley [15] with Sarmiento et al's modification [14][table 2].

RESULTS: From august 2007 to March 2012, eighty patients of distal end radius fractures were included in our study. The mean age of the patients taken up for the study was 42.6 years with the youngest patient being 20 years and the oldest being 70 years. There were 28 male patients (35\%) and 52 female patients (65\%). The right limb was affected in 58 cases (73\%) and left limb in 22 cases $(27 \%)$. The mode of injury was fall in 54 cases $(68 \%)$, road traffic accident in 26 cases (32\%). 16 fractures (20\%) were classified as AO type A, 12 fractures(15\%) as AO type B and 52 fractures (65\%) as AO type C. Ulnar Styloid was fractured in 24 cases $(30 \%)$ and intact in 56 cases (70\%). Out of 24 cases of ulnar styloid fractures, 7 fractures were from base or below the base of ulnar styloid. Most of the cases were operated on the same day or the next day of attending the OPD or the emergency. Out of the 80 cases, 68 cases (85\%) were operated within a week of injury and 12 cases (15\%) between 8-14 days. The delay, if any was on the part of the patients presenting late. The average duration of follow up was 62.5 weeks with minimum of 42 weeks and maximum of 78 weeks.

The residual dorsal tilt (from a neutral of 0 degrees) of the distal radial articular surface varied from 4 degrees to 26 degrees. The dorsal tilt decreased from an average of $13^{0}$ before the reduction to an average of $0.6^{0}$ at the last follow up evaluation. The goal of reduction was to correct the dorsal tilt to at least a neutral angle i.e. to achieve a residual dorsal tilt of $0^{0}$. The patients in whom the tilt was restored to the normal palmar tilt as of the uninjured side were also assigned a residual dorsal tilt of 0 degrees. Postoperatively the dorsal tilt could be corrected to the anatomical palmar tilt or at least a neutral angle in 68 patients (85\%) while in 12 patients $(15 \%)$ the dorsal tilt could not be restored even to a neutral angle. Out of these 12 patients, 8 had an AO type C fractures while 4 had an AO type A fractures. At the final follow up, four patients $(5 \%)$ had some loss of correction of dorsal tilt. These patients had a comminuted 
intra-articular fracture (AO Type C). In 95\% of the patients the correction of tilt achieved at surgery was maintained till healing.

The radial shortening varied from $4 \mathrm{~mm}$ to $26 \mathrm{~mm}$. It decreased from an average of 11 $\mathrm{mm}$ before the reduction to an average of $0.65 \mathrm{~mm}$ postoperatively and to $0.8 \mathrm{~mm}$ at the last follow up. In 4 patients (5\%) there were average $4 \mathrm{~mm}$ of collapse of radial length from the immediate postoperative to the final follow up period. These patients had AO type $\mathrm{C}$ fractures. $95 \%$ of the fractures maintained their postoperative radial length till union.

The loss of radial inclination varied from 0 degrees to 20 degrees. It decreased from an average of 12.1 degrees before reduction to an average of 0.9 to 1 degree postoperatively at the last follow up. In 4 patients (6\%) there was loss of average 3 degrees of correction of radial inclination. These patients had an AO Type C fracture.

On clinical evaluation 8 patients $(10 \%)$ had prominent ulnar styloid while 8 patients $(10 \%)$ had residual dorsal tilt. No patients had radial deviation of hand. Subjectively, out of 80 patients, 56 patients $(70 \%)$ had excellent, 20 patients $(25 \%)$ had good, and 4 patients $(5 \%)$ had fair results. Objective results are given in table 3.

According to the Sarmiento's modification of Lind Strom Criteria 68 patients (85\%) had excellent restoration of anatomy, 8 patients (10\%) had good restoration and 4 had fair (5\%) restoration of anatomy. Thus $95 \%$ patients had excellent to good alignment of fragments and reduction could not be achieved in $5 \%$ patients resulting in fair or poor results. On functional scoring by demerit point system of Gartland and Werley with Sarmiento et al's modification 60 patients (75\%) had excellent, 12 good (15\%) and 8 patients had fair (10\%) restoration of functions. Poor function correlated with residual displacement and poor patient compliance.

DISCUSSION: Fractures of the distal radius have been discussed in Orthopaedic literature for over 200 years [16]. The fracture patterns were described even before the advent of radiography. There is no tailor-made solution for all fractures of the distal radius. Since anatomical reconstruction is a prerogative for good functional outcome, it is important to reconstruct the anatomy of the distal radius as good as possible, especially in the active patient. In 1987 Short et al in their study noted that, reversal of the normal palmar tilt of the distal end of the radius has deleterious effects. In mechanical studies using pressure-sensitive film, a considerable transfer of load occurred onto the ulna with progressive dorsal angulation of the distal end of the radius. With a 45-degree dorsal angulation deformity, 65 per- cent of the axial load across the carpals is directed onto the ulna. The remaining loads on the radius were observed to be eccentric and concentrated on the dorsal aspect of the scaphoid fossa. Clinically, this may result in pain at the radiocarpal articulation, as well as in limited grip strength, if the angulation is not reduced. [17]

Margaliot et al [18] had performed a meta-analysis on outcomes of external fixators versus plate osteosynthesis for unstable distal radius fractures. They concluded that there was no evidence to support that the use of plate osteosynthesis is superior to external fixator. However, there were significantly higher rates of postoperative neuritis, infections, pin loosening and hardware failure for the external fixator groups. Tendon rupture and tenosynovitis were more commonly seen in the ORIF group. Villar RN et al [19] reported concomitant ulnar styloid fractures in up to fifty percent of distal radius fractures. The effect of ulnar styloid fractures on functional end results has been variable. The vast majority of ulnar styloid fractures probably heals with fibrous union and remains asymptomatic. Tsukazaki et al 
[20] in their study found no effect on the outcome of grip strength or range of motion in 25 of 44 fractures of the ulnar styloid with established nonunions at follow up.

In our study, ulnar styloid was involved in 24 cases (30\%), in which 7 fractures were from base or below the base of styloid process. Only these 7 fractures were fixed. 3 of which was managed by tension band wiring and 4 was managed by percutaneous $\mathrm{K}$ wire fixation. All seven patients had early supination-pronation movement and grip strength as compared with other seventeen.

The study of Rozental TD et al [21] showed that all patients of distal radius fracture managed by volar plating achieved excellent and good results on the Gartland and Werley scoring system, indicating minimal impairment in activities of daily living.

In our study according to the Demerit point system of Gartland and Werley for the functional evaluation, 60 patients (75\%) had excellent, $12 \operatorname{good}(15 \%)$ restoration of functions. 8 patients had fair $(10 \%)$ and no patient had poor $(0 \%)$ functions in our study. Sixteen patients had a residual clinical deformity in terms of prominent ulnar styloid/residual dorsal tilt and/or radial deviation of the hand. Functionally, out of 16, eight patients had good functional outcome and 8 patients had fair results. Out of 16, six were presented after 2 weeks of injury and out of 16; eight were grossly comminuted (AO type $\mathrm{C}$ ). Four of these patients had reported $>14$ days after the injury and was grossly displaced. Two of these patients, was however a fresh injury, but the fracture was grossly comminuted intra-articular fracture.

Subjectively 76 patients (95\%) had good to excellent results. 4 patient (5\%) had fair result who also had residual clinical deformity due to inadequate initial reduction, and had presented 7 days following trauma with a grossly displaced fracture but was non compliant to the postoperative protocol and exercise program. None of the patients had poor result.

Objectively, loss of movements, pain at distal radio-ulnar joint and loss of grip strength correlated with the age of the patient, severity of fracture, the patients reporting late, inadequate restoration of anatomy and poor patient compliance.

Three patients suffered from stitch line superficial infection which was treated by giving intravenous antibiotic. 2 patients were suffered from reflex sympathetic dystrophy which was treated symptomatically with NSAIDs, active/passive exercises of wrist and physical therapy.

Joint stiffness was present in 9 patients, 6 of whom had a comminuted intra-articular fracture (AO Type $\mathrm{C}$ ) and 3 had AO type A fracture. Joint stiffness was due to incongruency of the articular surface in intra-articular fractures or poor reduction in extra-articular fracture and poor patient compliance. Out of 6 patients in AO type $C$ which had joint stiffness, 4 developed posttraumatic arthrosis on long term follow up. Paraesthesia in distribution of median nerve was present in 3 patients which recovered during the course of treatment.

In conclusion, 95\% anatomical and $90 \%$ functional, excellent to good results, suggests that stabilizing the fracture fragments with volar plate and screws in the management of the fractures of distal radius, is an effective method to maintain the reduction till union and prevent collapse of the fracture fragments, even when the fracture is grossly comminuted/intraarticular/unstable and/or the bone is osteoporosed.

This technique emphasizes that open reduction and internal fixation with volar plating has excellent functional outcome with minimal complications thus proving that it is the prime modality of treatment for distal radius fractures. The procedure is applicable for AO types A, B and $\mathrm{C}$ fractures of the distal radius, in young patients with a good bone stock as well as in elderly osteoporotic patients. 


\section{REFERENCES :}

1. Hollings worth R, Morris J:the importance of ulnar side of wrist in fracture of distal radius injury: 263-266,1976.

2. Linschied RL:kinematic consideration of the wrist clin orthop 202:27-39,1986.

3. Colles A. On the fracture of the carpal extremity of the radius. Edinburgh Med Surg 1814;10:182-6.

4. Swiontkowski MF. Increasing rates of forearm fractures in children. JAMA 2003;24;290(24):3193.

5. Solgaard S, Petersen VS. Epidemiology of distal radius fractures Acta Orthop Scand 1985;56(5):391â€“393.

6. Mensforth RP, Latimer BM. Hamann-Todd Collection aging studies: osteoporosis fracture syndrome. Am J Phys Anthropol 1989;80(4):461â€“479.

7. Gartland JJ, Werley CW. Evaluation of healed Colles' fractures. J Bone Joint Surg Am 1951;33(4): 895-907.

8. Frykman GK. Fracture of the distal radius including sequelae shoulder hand finger syndrome. Disturbance in the distal radioulnar joint and impairment of nerve function. A clinical and experimental study. Acta Orthop Scand Suppl 1967;108:1-155.

9. Knirk J, Jupiter J. Intraarticular fractures of the distal end of the radius in young adults. J Bone Joint Surg Am 1986;68(5):647-59.

10. Bacorn RW, Kurtzke JF: Colles' Fracture: A study of two thousand cases from the New York states Compensation Board. J Bone Joint Surg 1953; 35A: 643-658.

11. Fernandez DL: Correction of posttraumatic wrist deformity in adults by osteotomy, bone grafting and internal fixation. J Bone Joint Surg 1982;64A:1164 - 1178

12. Zemel NP: The prevention and treatment of complications from fractures of the distal radius and ulna. Hand Clin. 1987;3:1 - 11.

13. Sarmiento A, Pratt GAW, Berry NC, Sinclair WF: Colles' fractures: Functional Bracing in supination. J Bone Joint Surg 1975;57A:311-317.

14. Gartland JJ, Werley CW. Evaluation of healed Colles' fractures. J Bone Joint Surg Am 1951;33(4): 895-907.

15. Robert W. Bucholz, MD, James D Heckman, MD: Rockwood Greens Fractures in Adults. $5^{\text {th }}$ edition, Lippincott Williams \& Wilkins 2001 Volume I: 815 - 867.

16. Short WH, Palmer AK, Werner FW and Murphy DJ: A Biomechanical Study Of distal radius Fractures. J Hand Surg., 12A; 529-534, 1987.

17. Margaliot Z, Haase SC, Kitsis SV, Kim HM, Chung KC. A metanalysis of outcomes of external fi xation versus plate osteosynthesis for unstable distal radius fractures. J Hand Surg [Am] 2005;30:1185-99.

18. Villar RN, Marsh D, Rushton N, Greatorex RA: Three years after Colles' Fracture. A prospective review. J Bone Joint Surg 69B: 635-638.

19. Tsukazaki T, Takagi, Iwasaki K: Poor correlation between functional results and radiographic findings in Colles' fracture. J Hand Surg 1993;18B:588-591.

20. Rozental T, Blazar P. Functional outcome and complications after volar plating for dorsally displaced, unstable fractures of the distal radius. J Hand Surg [Am] 2006;31(3):359-65. 
[TABLE 1] ANATOMICAL EVALUATION BY SARMIENTO'S MODIFICATION OF LIND STORM CRITERIA

\begin{tabular}{|l|l|l|l|l|}
\hline & Deformity & $\begin{array}{l}\text { Residual dorsal } \\
\text { tilt }\end{array}$ & $\begin{array}{l}\text { Radial } \\
\text { shortening }\end{array}$ & $\begin{array}{l}\text { Loss of radial } \\
\text { inclination }\end{array}$ \\
\hline Excellent & $\begin{array}{l}\text { No } \\
\text { insignificant }\end{array}$ & $0^{0}$ & $<3 \mathrm{~mm}$ & $<5^{0}$ \\
\hline Good & Slight & $1^{0}$ to $10^{0}$ & 3 to $6 \mathrm{~mm}$ & $5^{0}$ to $9^{0}$ \\
\hline Fair & Moderate & 11 to 14 & 7 to $11 \mathrm{~mm}$ & $10^{0}$ to $14^{0}$ \\
\hline Poor & Severe & At least $15^{0}$ & At least $12 \mathrm{~mm}$ & $>14^{0}$ \\
\hline
\end{tabular}

[TABLE 2] DEMERIT POINT SYSTEM USED TO EVALUATE END RESULTS OF HEALED COLLES' FRACTURES

\begin{tabular}{|c|c|}
\hline RESULT & POINTS \\
\hline \multicolumn{2}{|l|}{ RESIDUAL DEFORMITY } \\
\hline Prominent Ulnar Styloid & 1 \\
\hline Residual Dorsal Tilt & 2 \\
\hline Radial Deviation of Hand & 2 to 3 \\
\hline Point Range & 0 to 3 \\
\hline \multicolumn{2}{|l|}{ SUBJECTIVE EVALUATION } \\
\hline Excellent: no pain, disability or limitation of motion & 0 \\
\hline Good: Occasional pain, slight limitation of motion, no disability & 2 \\
\hline $\begin{array}{l}\text { Fair: Occasional pain, some limitation of motion, feeling of weakness } \\
\text { in wrist, no particular disability if careful, activities slightly }\end{array}$ & 4 \\
\hline Poor : Pain, limitation of motion, disability, activities more or less & 6 \\
\hline 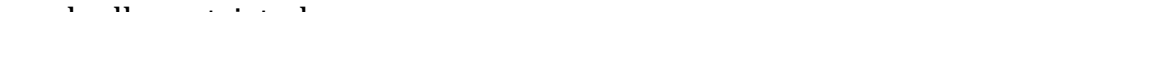 & 0 to 6 \\
\hline \multicolumn{2}{|l|}{ OBJECTIVE EVALUATION* } \\
\hline Loss of Dorsiflexion & 5 \\
\hline Loss of Ulnar Deviation & 3 \\
\hline Loss of Supination & 2 \\
\hline Loss of Palmar Flexion & 1 \\
\hline Loss of Radial Deviation & 1 \\
\hline Loss of Circumduction & 1 \\
\hline Loss of Pronation & 2 \\
\hline Pain in Distal Radioulnar Joint & 1 \\
\hline Grip Strength $-60 \%$ or less of opposite side & 1 \\
\hline Point Range & 0 to 5 \\
\hline \multicolumn{2}{|l|}{ COMPLICATIONS } \\
\hline \multicolumn{2}{|l|}{ Arthritic Change } \\
\hline Minimum & 1 \\
\hline Minimum with Pain & 3 \\
\hline Moderate & 2 \\
\hline Moderate with pain & 4 \\
\hline
\end{tabular}




\begin{tabular}{ll}
\hline Severe & 3 \\
Severe with pain & 5 \\
Nerve Complications (Median) & 1 to 3 \\
Poor Finger Functions Due to Cast & 1 to 2 \\
& 0 to 5 \\
END RESULT POINT RANGES & \\
Excellent & 0 to 2 \\
Good & 3 to 8 \\
Fair & 9 to 20 \\
Poor & 21 \& Above \\
\hline
\end{tabular}

*The objective evaluation is based on the following ranges of motion as being the minimum for normal function: dorsiflexion $45^{\circ}$; palmar flexion $30^{\circ}$; radial deviation $15^{0}$; ulnar deviation $15^{0}$; pronation $50^{\circ}$; supination $50^{\circ}$

[Table 3] objective evaluation

\begin{tabular}{ll}
\hline Objective parameter & No. of patients \\
\hline Loss Of Dorsiflexion ( $<45$ degrees) & 0 \\
\hline Loss Of Palmar Flexion ( $<30$ degrees) & 11 \\
\hline Loss Of Ulnar Deviation ( $<15$ degrees) & 3 \\
\hline Loss Of Radial Deviation ( $<15$ degrees) & 7 \\
\hline Loss Of Supination (<50 degrees) & 4 \\
\hline Loss Of Pronation (<50 degrees) & 4 \\
\hline Loss Of Circumduction & 4 \\
\hline Pain at DRUJ & 0 \\
\hline Grip Strength $\leq 60 \%$ of opp. Side & 4 \\
\hline
\end{tabular}

\section{[table 4] Complications}

\begin{tabular}{lc}
\hline Reflex Sympathetic Dystrophy & 2 \\
Joint stiffness & 9 \\
Impingement of tendons & nil \\
Median Nerve Complications & 3
\end{tabular}




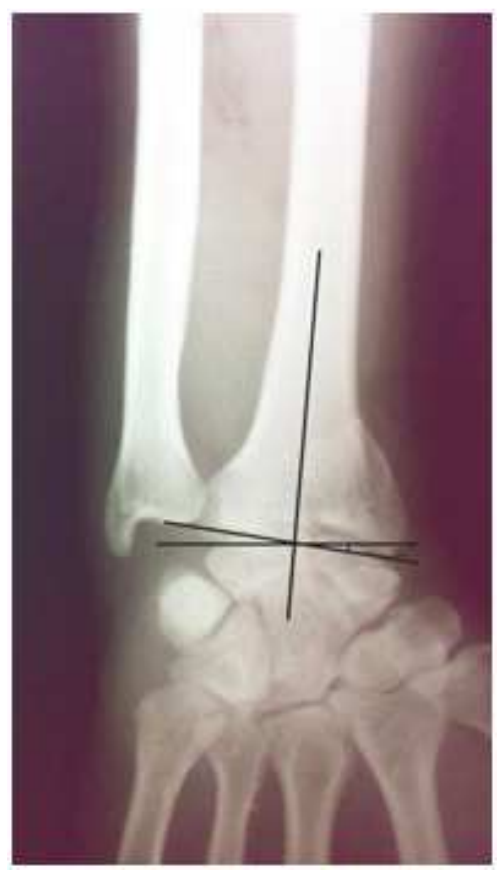

(A)

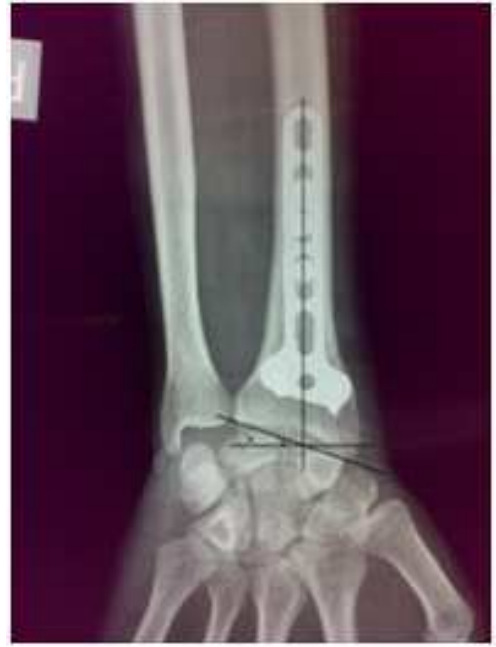

(C)

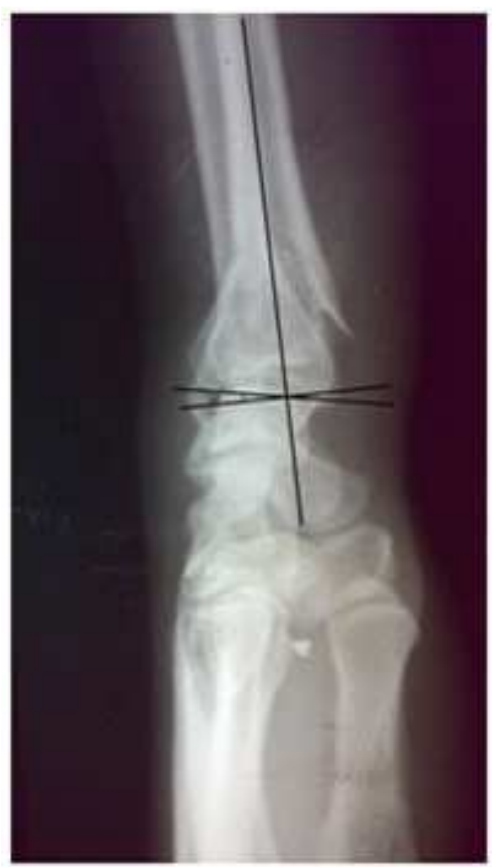

(B)

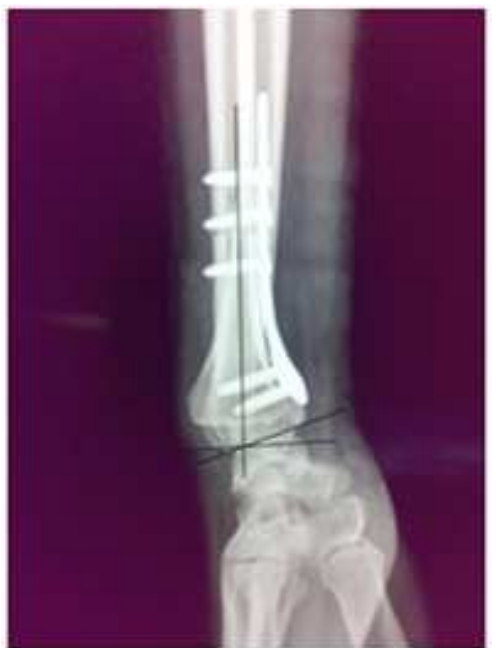

(D)

40/M with fracture distal end radius managed by volar plating. (A) pre-operative X-ray AP view. (B) lateral view (C) post operative X-ray AP view (D) lateral view. 


\section{ORIGINAL ARTICLE}

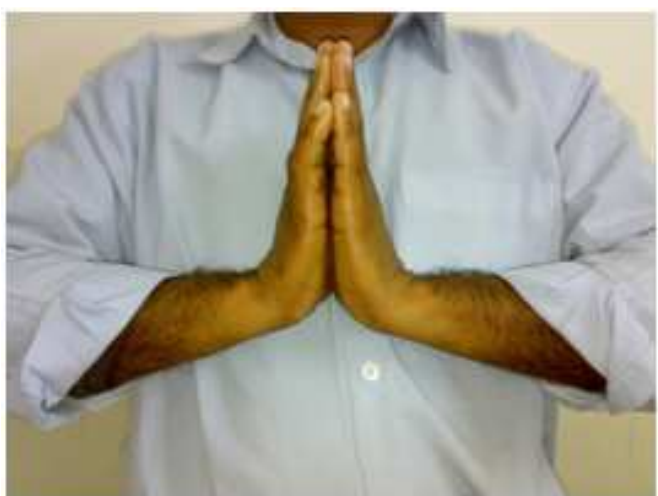

(A)

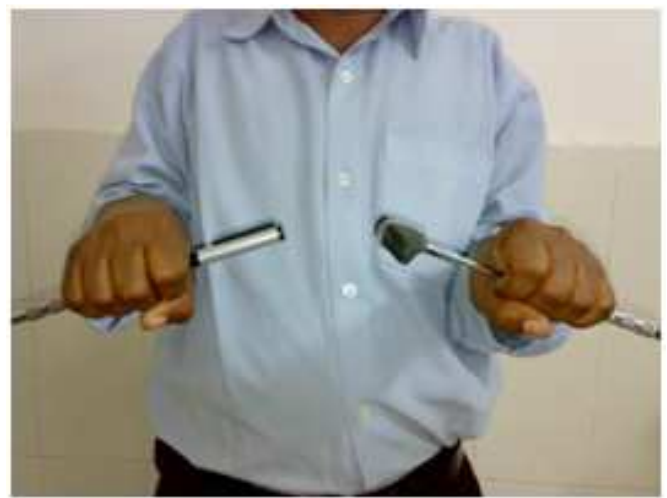

(C)

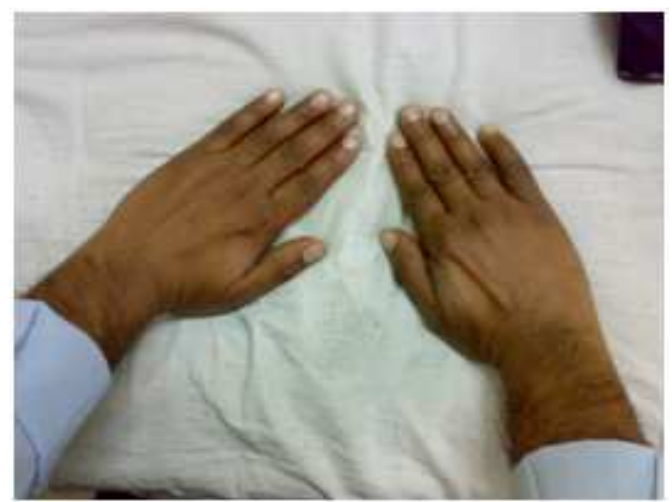

(E)

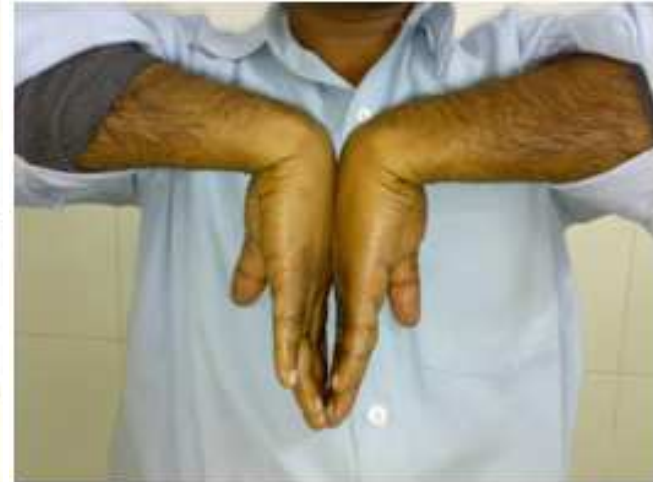

(B)

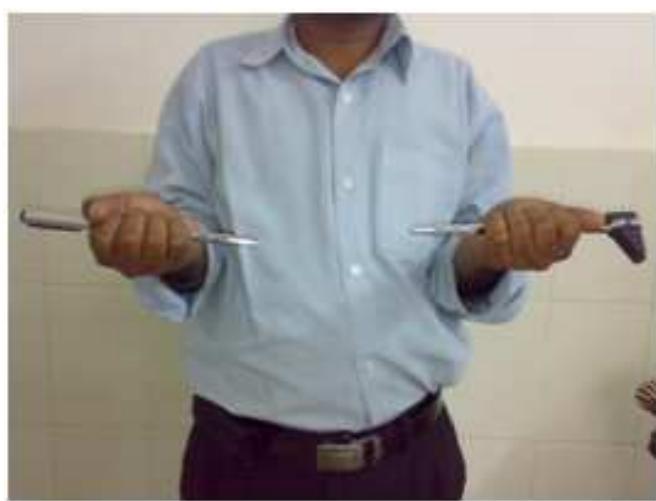

(D)

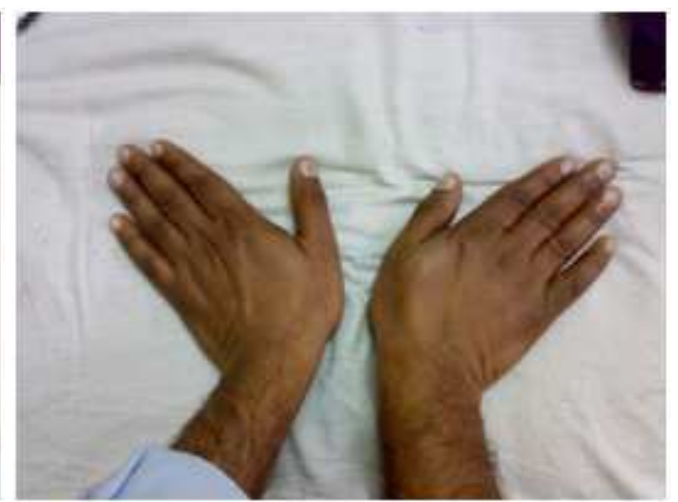

(F)

Same patients as above with functional result at 6 month (A) dorsiflexion (B) palmar flexion(C) pronation (D) supination (E) radial deviation (F) ulnar deviation. 